\title{
UM OLHAR HUMANO SOBRE A SUBJETIVIDADE, RACIONALIDADE E CIÊNCIA
}

\author{
Tiziana Cocchieri (Doutoranda em Filosofia - PUCRS) ${ }^{1}$ \\ Prof. Dr. Eduardo Luft (Orientador) - PUCRS
}

\section{RESUMO}

Foucault abre alguns sulcos no corpo da ciência para construir um discurso sobre o indecifrável, que considera o que há de sujeito nas pretensões de racionalidade e nas descrições de caráter sistematizado da lógica clássica estabelecida como linguagem válida. Por sua vez, ao escapar da compreensão, grosso modo, do esquema positivado no qual a ciência se fundamenta, o tema sobre a natureza do sujeito vem à tona como conceito revisitado, para a análise do que seria a natureza da racionalidade percebida em contexto contemporâneo. A pretensão de universalidade que se realizaria na contingência é um dos problemas a serem apontados. Em outro dizer, o discurso da lógica, como validando a si mesmo em sua própria autonomia axiomática, parece ser uma pretensão intangível. Ao considerarmos que sujeitos constroem as narrativas pertinentes às teorias científicas, parece relevante configurar uma topografia da perspectiva desse sujeito da ciência; assim como de seu estofo conceitual para dar vistas ao que constitui como de natureza legitimada, como portadora de sentenças válidas, em que há a transliteração da esfera qualitativa da experiência para a generalidade da quantificação.

Palavras-Chave: Subjetividade. Racionalidade. Ciência.

Neste artigo, retomamos a problemática do sujeito a partir das reflexões de Foucault, reconstruindo os conceitos que corroboram para a tese que sustenta que o sujeito é também o produtor da ciência. Buscamos enfatizar que a ciência seja percebida ao longo de seu processo de formalização em sua relação indissociável entre o sujeito e o objeto ao qual se dedica a pesquisar.

Com intuito de "escavar" o conceito de subjetividade, tal qual o fez com outros em sua proposta "arqueológica", o filósofo francês apresenta como tema paralelamente imbricado à história da sexualidade, a construção do sujeito. Mais especificamente, nos dedicaremos a extrair argumentos a partir da abordagem da construção da subjetividade expressa por Foucault. O tema sobre subjetividade aparece desenvolvido pari passu a temas como a sexualidade, o poder e as relações entre coisas e pessoas, com exposições argumentativas extensas e complexas. Nosso intuito é o de extrair fragmentos de seu pensamento que desemboquem na configuração dos dispositivos de poder quem envolvem os processos de subjetivação, que compõe a sociedade moderna da qual somos herdeiros. Para Foucault, convém discernir quais sejam as fontes de formação conceitual do sujeito, e para tanto propõe uma análise dos processos do que concerne à discursiva da subjetivação. Neste sentido, o filósofo analisa que são indissociáveis os processos de subjetividade e

\footnotetext{
${ }^{1}$ E-mail: tiziana.cocchieri@acad.pucrs.br e tiziana@unir.br
} 


\section{SEMINÁRIO DE PESQUISA EM CIÊNCIAS HUMANAS - SEPECH \\ Humanidades, Estado e desafios didático-científicos \\ Londrina, 27 a 29 de julho de 2016}

subjetivação, pois não haveria constituição de sujeito moral sem um processo baseado em pressupostos que fundamentem a estrutura da formação e homologação dos valores que perfazem um coletivo de subjetividades. Foucault argumenta e propõe a questão no trecho abaixo:

Paradoxo teórico e metodológico também: as longas discussões sobre a possibilidade de constituir uma ciência do sujeito, a validade da introspecção, a evidência da experiência, ou a presença para si da consciência respondiam sem dúvida, a esse problema que era inerente ao funcionamento dos discursos de verdade, em nossa sociedade: poder-se-ia articular a produção da verdade, segundo o velho modelo jurídico-religioso da confissão, e a extorsão da confidência segundo a regra do discurso científico? $(1999$, pp. 62,63)

Ao escapar da compreensão do esquema positivado como fonte de crença justificada no qual a ciência está fundamentada para dizer o que as coisas são, Foucault, grosso modo, parte da história para construir o tema sobre a natureza da análise do sujeito. Neste sentido, ao adotar um padrão rígido de configuração do sujeito, ou negligenciar sua análise, a proposta cientificizada validaria a si mesma com bases em sua autoridade quanto ao dizer como as coisas são, sem recorrer a um exame mais profundo das estruturas subjacentes da formação do sujeito enquanto sujeito, negligenciado as bases históricas que narram todo esse processo de formação. A pretensão de universalidade que se realiza nas condições recorrentes de necessidade, não se comporta da mesma maneira em ocasiões que envolvem a contingência, incluindo a presença do próprio pesquisador ao observar, avaliar e descrever seu objeto ou método não poderia negar a presença de elementos contingenciais. Mediante este modelo, o agente da pesquisa, aparentemente, gozaria de uma natureza imbuída de neutralidade, ou seja, parafraseando o estilo irônico foucaultiano, um ser humano não tão humano assim.

O que parece ser uma pretensão intangível, paradoxalmente se efetua como recorte arbitrário da realidade. Já que a ciência se pretende séria, ampla e em correspondência com a representação da realidade, a análise do sujeito como parte do processo de pesquisa não poderia ser pensada sem um pressuposto do sujeito; este protagoniza sua existência em todo âmbito que envolve a racionalidade. Em outro viés, a propagação de uma visão de mundo que entende a ciência como porta voz da verdade, em seu fundamento último, estaria também sob revisão, ainda que a partir de questões de natureza aporética, complexa e paradoxal que envolve as análises sobre sujeito e objeto.

Ao considerarmos a inserção da temática do sujeito no contexto da ciência, como parte do processo da pesquisa, ele próprio torna-se um objeto de análise. Sendo assim, ao lançar luz sobre a natureza do sujeito, com intuito de dizer o que o mundo é, haveria a necessidade de somar à objetividade própria da ciência, o olhar perspectivado das muitas áreas que se ocupam da descrição da ontologia do sujeito; áreas do saber diversas, que estariam mais para as aporias do que para as positivações pretendidas e simplificadas. Neste ponto, convém evocar as palavras de Foucault:

$\mathrm{Na}$ experiência moderna, a possibilidade de instaurar o homem num saber, o simples aparecimento dessa figura nova no campo da 


\section{SEMINÁRIO DE PESQUISA EM CIÊNCIAS HUMANAS - SEPECH \\ Humanidades, Estado e desafios didático-científicos \\ Londrina, 27 a 29 de julho de 2016}

epistémê, implica um imperativo que importuna interiormente o pensamento; pouco importa que ele seja cunhado sob as formas de uma moral, de uma política, de um humanismo, de um dever de se incumbir do destino ocidental, ou da pura e simples consciência de realizar na história uma tarefa de funcionário; o essencial é que o pensamento seja, por si mesmo e na espessura de seu trabalho, ao mesmo tempo saber e modificação do que ele sabe, reflexão e transformação do modo de ser daquilo sobre o que ele reflete. Ele põe em movimento, desde logo, aquilo que toca: não pode descobrir o impensado, ou ao menos ir a sua direção, sem logo aproximá-lo de si - ou talvez ainda, sem afastá-lo, sem que o ser do homem, em todo o caso, uma vez que ele se desenrola nessa distância, não se ache, por isso mesmo, alterado. (1999, p. 450-451)

Nas reflexões de Foucault se tem uma dimensão do que seria na ciência convencionalmente praticada e historicamente negligenciada sua condição necessária para dar curso às construções teóricas em que as bases estão depositadas em crenças justificadas de uma construção sintática da linguagem formal, porém sem sujeito. Todavia, não é suficiente a prática de uma apresentação universalmente esquematizada do sujeito e exemplificada na condição de neutralidade do pesquisador, ao menos não para que seja representada uma correspondência com a realidade. Em outro dizer, sujeito e objeto, em análise profunda, são dialeticamente indissociáveis, assim como a necessidade e a contingência. Sem buscar saber o que é ser um sujeito, a própria pesquisa se vê limitada em suas perspectivas, inclusive à cerca das observações e inferências extraídas do processo que envolve o objeto pesquisado.

$\mathrm{O}$ argumento defendido por Foucault é que o sujeito está envolvido em uma história, que, por sua vez, está enredado em processos temporais de subjetivação, sujeito a construção de valores e orientação moral. Isso significa dizer que, o sujeito faz parte de uma tessitura conceitual, que não poderia ser orquestrada apesar de sua pretensão de objetividade e correspondência com a realidade. A ordenação na qual a ciência é posta, como comprovação de verdades sobre a realidade, não está nem aquém, nem além da vida vivida; são sujeitos que constroem teorias e não autômatos misantropos. Há um arejamento sobre o modo de se fazer ciência na contemporaneidade, considerando as imbricações das áreas de conhecimento que são entendidas e tratadas como permeáveis, incluindo em seus processos ontológicos e metodológicos, de modo que os limites que separam um saber de outro são de difícil percepção. Logo, a perspectiva conservadora que ainda se faz presente no contexto nacional de pesquisa, na área da epistemologia, resiste às instituições que adotam o modo de pesquisa trans, multi e interdisciplinares, que inclusive são incentivados pelas instituições públicas de fomento na área de filosofia. O pesquisador de gabinete está fadado a desaparecer.

Nesse sentido, tanto a adoção de um modelo que assimila o elemento subjetividade como o que possui pretensão de profilaxia objetivável, ambos estão repletos de capítulos em aberto, esboços cifrados, incompreendidos, e cheios de ambiguidades, ou seja, cheios de elementos que se comportam de modo não esquematizável, elementos contingentes. De qualquer modo, como a tese defendida é de que o sujeito não está dissociado do mundo no qual está inserido, a representação 


\title{
XI SEMINÁRIO DE PESQUISA EM CIÊNCIAS HUMANAS - SEPECH \\ Humanidades, Estado e desafios didático-científicos \\ Londrina, 27 a 29 de julho de 2016
}

mais fiel da realidade parece ser mesmo a descontinuidade, a ruptura, o aparentemente contínuo arbitrário.

O sujeito está inserido em um cosmos que não expõe seu conteúdo em linguagem elementar, tampouco apresenta uma sintaxe universal, pois, se assim fosse, tudo faria sentido, seria tão somente uma questão propedêutica, de levar adiante o conhecimento a outras gerações ulteriores de acordo com a linguagem vigente. Os elementos que causam aversão aos analíticos e conservadores homens do conhecimento é desembocar num caminho como este, de se verem enlaçados na vertigem da licença poética, da ambiguidade e do não trilhado dedutivamente, com bordas limitadas por abismos de relações inusitadas. No entanto, em relação contraditória estas mesmas bordas são as que configuram o caminho para as zonas de criatividade, que envolvem a lógica das descobertas, os processos abdutivos que pleonásticamente geram hipóteses plausíveis, mudanças de paradigma e consequentemente revoluções científicas.

Nestes casos de linhas de afinidade e continuidade, ou de repulsa e particularização (descontinuidade), são diagramáticos os esquemas configurados a partir destes elementos de linha-limite. Sem a demarcação de suas bordas, de suas zonas de fronteira, não se poderia discernir um objeto de outro, um fenômeno de outro e assim por diante, pois o que temos percebido, tal qual dito há tempos por $\mathrm{Hegel}^{2} \mathrm{e}$ parafraseado por Marx, as coisas sólidas são feitas de relações, aliás, nos parece que tudo se configura por meio de relações; assim também tem sido observado pelos da ciência contemporânea. ${ }^{3}$ Parece ser isso o que Foucault chama de proto-racional, a percepção das relações que são aparentemente inusitadas. Em graus de sutileza cada vez mais apurados, o estudo das relações ao definir os limites do que seja um objeto, considerando que tudo está de algum modo ligado ao todo, tem caráter de natureza metaforicamente arqueológico, pois implicaria em construir relações que remontam a períodos anteriores, acompanhado de revisão histórica.

\begin{abstract}
A primeira forma de filosofia manifestou-se de início no empreendimento fichtiano em que a totalidade do domínio transcendental é geneticamente deduzida das leis puras, universais e vazias do pensamento: por aí se abriu um campo de pesquisas por onde se tenta, quer reduzir toda reflexão transcendental à análise dos formalismos, quer descobrir na subjetividade transcendental o solo de possibilidade de todo formalismo. Quanto à outra abertura filosófica, apareceu primeiramente com a fenomenologia hegeliana, quando a totalidade do domínio empírico foi retomada no interior de uma consciência que se revela a si própria como espírito, isto é, como campo ao mesmo tempo empírico e transcendental. (FOUCAULT, 1999, p. 340).
\end{abstract}

\footnotetext{
${ }^{2}$ Cirne-Lima apresenta este fragmento do pensamento de Hegel de forma bastante esclarecedora: "Hegel - e eu com ele - começa um movimento que irá se estender por todo o restante da Ciência da Lógica: tudo que nos parece sólido se dissolve em relações”. (CIRNE-LIMA, 2006, p.57)

${ }^{3}$ Há uma vasta literatura a respeito da adoção desta visão cosmogônica do mundo como sistema. Para aprofundamento no tema, sugiro a leitura da Coleção CLE - Auto-organização: Estudos interdisciplinares, produzida pelo Centro de Lógica, Epistemologia e História da Ciência da UNICAMP.
} 


\section{SEMINÁRIO DE PESQUISA EM CIÊNCIAS HUMANAS - SEPECH \\ Humanidades, Estado e desafios didático-científicos \\ Londrina, 27 a 29 de julho de 2016}

A compartimentalização de áreas de conhecimento só poderia servir a uma utopia de um mundo com pretensões rectam et. Na realidade, o mundo não se configura por meio de placas que nos avisam em qual dos terrenos do conhecimento estamos transitando, estas delimitações e mapeamentos ao qual estamos habituados possui certo grau de arbitrariedade, pois, de que outro modo se poderia dizer: até aqui é a biologia, daqui ali, a química, e assim por diante. Estas construções de áreas são territoriais e não factuais, são necessárias para fins didático-metodológicos, pois havemos de ensinar a outras gerações ulteriores, mas não são limites fixos, vão se alterando de acordo com a agudez de nossa percepção. A perspectiva altera os limites e a percepção do olhar, o que também se caracteriza como ordenação contingente, se aprimora conforme a compreensão do todo de expande e as ferramentas se tornam mais sofisticadas esticando este olhar ou encolhendo-o a escalas nanotecnológicas.

Esticando um pouco mais a malha que perfaz a formação das teorias científicas, ao analisar sua estrutura subjacente é pertinente analisar conjuntamente a adequação do método de pesquisa aos seus fins da mesma pesquisa. De modo bastante geral, não é muito comum que cientistas se debrucem sobre análises na área da epistemologia, ou seja, o interesse maior estaria na descoberta das coisas, no entendimento do mundo testável empiricamente, em comporem teorias que ratifiquem suas observações, ao invés de se ocuparem em questões que gravitam em torno da pesquisa de como podemos conhecer, melhor raciocinar, ou saber que sabemos algo. Qual a melhor forma de raciocinar, ou como se dá a possibilidade de conhecermos o mundo, não parece ser tema muito atraente, principalmente à área das ciências duras. No entanto, o que chamamos de epistemologia é um dos pilares para a construção da visão de mundo vigente que influencia de modo diretivo os processos de análise da realidade. E para entrarmos neste campo, a ontologia oferece suporte para a abordagem mais profunda sobre a natureza do que há no mundo, enquanto que a fenomenologia, área com a qual os cientistas se ocupam, é ulterior.

Transitando na área da fenomenologia, assim como a ciência que adota o falibilismo como corrente, a epistemologia deveria seguir caminho semelhante. $\mathrm{Ou}$ seja, deveria considerar que os processos de raciocínio e lógicas disponíveis poderiam ser revisadas a cada formulação mais abrangente e razoável, ou mesmo submeter-se à análise de aplicação de uma lógica especificada para cada contexto peculiar, com vistas aos fins. Não pretendemos com isso cair em digressão reconstruindo a história da lógica para desenvolver nossa hipótese, mas, enfatizar que a história da epistemologia e da lógica seguem par in passo a história da ciência. Com isso pretendemos questionar, onde está o sujeito e os processos de subjetivação sob a luz dos raciocínios tidos como logicamente justificáveis e aceitáveis formalmente?

Interessante que Foucault (1977) levanta o tapete e sopra a poeira para por à mostra a aparente solidez das teorias que representam a realidade, construídas a partir de supostas verdades seguras e tentativas de demarcações justificadas. Em outro dizer, de modo bastante geral, a partir de um recorte aparentemente arbitrário da realidade, proposto pelo que se entende por conhecimento cientificizado - por vezes delimitado por grupos em aceitação convencionada ${ }^{4}$ - os processos de subjetivação vão sendo

\footnotetext{
${ }^{4}$ Tipo de "denúncia" semelhante fizeram T. Kuhn e P. Feyerabend, quanto às demais implicações que envolvem o conhecimento cientificizado, apresentando de modo peculiar a cada qual a fragilidade das crenças oferecidas como seguramente justificadas pelas teorias científicas.
} 


\section{SEMINÁRIO DE PESQUISA EM CIÊNCIAS HUMANAS - SEPECH \\ Humanidades, Estado e desafios didático-científicos \\ Londrina, 27 a 29 de julho de 2016}

formados como em movimento circular, retroalimentando um esquema de relações que se pretendem necessárias, no entanto, construídas a partir de contingências, de valores que são colocados por meio de dinâmicas de poder, que seja ele de sedução, persuasão ou força. Neste sentido, como saber qual estrutura de racionalidade, por vezes confundida com o que seria a verdade solidamente comprovada, deva vigorar e criar raízes com peso de critério de relevância? Esta seguramente não é uma nova questão, porém continua a estar em aberto.

Conhecer e sujeitar faz parte de uma dialética perigosa, em que o saber e o poder não estão dissociados. Neste sentido, a proposta do que convém ser feito é colocar sob constante revisão e análise, nossos sistemas de racionalização e formulação de teorias, com intuito de extrair os interesses valorativos intrínsecos aos critérios de relevância estabelecidos por adoção. Enquanto admiramos e exaltamos os poderes da mente humana, seja buscada concomitantemente uma coerência para um fim último, que seria o bem estar-maior e da maioria das pessoas, qualidade de vida e um bem viver. Não seria este o fim último, o sumo bem desde a Grécia Antiga? Logo, Foucault começou por um caminho bastante pertinente ao retornar a este tempo para reconstruir os processos de subjetivação que revelam as características do sujeito de cada tempo, como dito anteriormente, que somos deles herdeiros.

Há uma objetividade na percepção do sujeito que se configura como padrão, o intuito não é de negar este aspecto e afundar em um processo de plena subjetivação, mas acrescentar sobre a percepção do padrão o olhar sobre si (sujeito), que é de fundamental importância na construção representacional e, consequentemente, para nosso propósito, nos processos de sistematização de teorias, pois discernir, diferenciar, configurar, são tarefas pertinentes ao ofício da pesquisa, que envolvem não somente a percepção, mas juízo, escolha, ainda que estejam submersas no inconsciente de seu autor ou grupo de autores, ou seja, alienadas. O que o caminho pela história perfaz é encontrar o fio que desemboca nos nossos processos contemporâneos de relação sujeito-objeto. O olhar sobre si acompanha esta revisão, e, segundo o pensamento de Foucault, ninguém está livre do olhar sobre si, seja em que época for.

Epimeleia heautou, gnothi seauton - ( $\gamma v \omega \theta \mathrm{\imath} \sigma \varepsilon \alpha v \tau o ́ v)$, conheça-te a ti mesmo, e ocupar-se de si mesmo não é um mote obsoleto como se poderia pensar, tampouco clichê, porém, pertinente e adequado para os contextos do pensar em todos os tempos, ao longo de toda história. Se acompanharmos o curso das narrativas, os contextos de subjetivação são diversos, e haveria de trazer à tona as narrativas - que é o que temos de recurso abundante numa revisão histórica- que influenciaram nossa visão sobre nós mesmos como sujeitos, tanto em sua acumulação quanto seletivamente.

Ambas as formas do termo epimeleia estão diretamente relacionados, eles são inseparáveis. Inclusive, pode ser considerado conhecer a si mesmo subordinar a cuidar de si mesmo, ou seja, o conhecimento de si mesmo é uma forma de cuidar de si mesmo. Da mesma forma, temos a

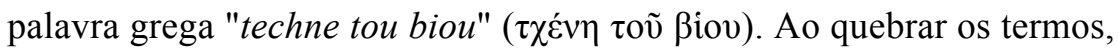
temos que encontrar primeiro o substantivo $\tau \chi \dot{\varepsilon} v \eta$ (arte, ciência, ou seja, o comércio, profissão). Por outro lado, temos a toṽ ßiov genitivo e o substantivo que significa vida. O termo "TEKHNE tou biou" é traduzido pela Latin ars vivendi, e está associada com o conceito de epimeleia, para lidar com si mesmo é inseparável da arte de viver, que trata da tradução do termo. Aprender a arte de viver é cuidar de si mesmo e da 


\section{SEMINÁRIO DE PESQUISA EM CIÊNCIAS HUMANAS - SEPECH \\ Humanidades, Estado e desafios didático-científicos \\ Londrina, 27 a 29 de julho de 2016}

vida é uma substância a modelar como arte. E a arte, TEKHNE ( $\tau \chi \varepsilon ́ v \eta)$, é inconcebível sem a vida. (FUENTES, 2011, p. 56) ${ }^{5}$.

Ao evocar o termo epimeleia, teknhe e ars vivendi, buscamos alterar a ordem do sujeito que serve à ciência para a ciência que está a serviço do viver bem e da arte do bem viver. Em princípio, as palavras estavam muito próximas, faziam parte de um mesmo léxico, transliteradas para os termos que estamos familiarizados seriam: conhecer a si, a técnica e a arte, que em algum momento foram separadas e passaram a habitar léxicos distintos, segundo o mapeamento em curso. Alterando a ordem destes fatores, se altera todo seu thelos.

Os conceitos ${ }^{6}$ apresentados são articulados e expressos em uma concatenação entre o que busca conhecer e o que há para ser conhecido, em que o ponto de partida para ampliar o conceito é ampliá-lo a partir de si. O sujeito que conhece a si pode descrever em palavras suas prerrogativas, valores, prioridades e afins. A pesquisa viria como a continuidade deste processo consciente, sem fragmentações, porém como uma forma de ser do outro que se distingue do eu, do si mesmo, do self, e se conjuga coletivamente. Em síntese, a compreensão do si mesmo levaria a uma maior clareza ao descrevê-lo e, consequentemente, ao descrevê-lo em palavras viria sequencialmente à familiaridade com o exercício da narrativa, ligando as palavras às coisas, e naturalmente se iria desenvolvendo com certa fluidez natural graus mais amplos e complexos de representação. Considerando que as teorias são feitas por pessoas, e pessoas criam palavras, palavras não são meras esquematizações, são também parte do processo de subjetivação.

Logo, o problema se desloca para outro ambiente, das coisas para as palavras; do cientista para o rapsodo em um mesmo sujeito. Porém, este deslocamento se desenvolve ainda concatenado ao ambiente anterior que se apresenta transliterado que aponta para uma interrogação: As palavras são arbitrárias e autônomas, independentes das coisas, ou as coisas estão presentes de uma maneira ou outra, interagindo par in passo com as palavras em processo contínuo de criação? Avançando em terreno especulativo, por meio de um experimento mental, as palavras poderiam ser agentes

\footnotetext{
${ }^{5}$ Tradução livre a partir do fragmento do texto original: “Ambas as formas del término epimeleia están directamente relacionadas, inseparables. Incluso puede considerarse el conócete a ti mismo subordinado al cuídate de ti mismo, es decir el conocimiento de uno mismo es una forma del cuidarse de sí. De igual

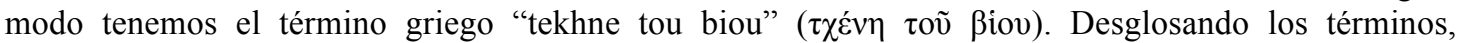
primeramente nos encontramos con el sustantivo $\tau \chi \varepsilon ́ v \eta$ (arte, ciencia, saber, oficio, profesión). Por otro lado, tenemos el genitivo đoṽ y el sustantivo ßíov que significa vida. El término "tekhne tou biou" es traducido por el ars vivendi latino, y está asociado al concepto de epimeleia, pues el ocuparse de uno mismo es indisociable del arte de vivir, que viene a ser la traducción de dicho término. Aprender el arte de vivir es ocuparse de uno mismo y la vida propia es una sustancia amodelar como arte. Y el arte, la tekhne ( $\tau \chi \varepsilon \dot{\varepsilon} \eta)$, es inconcebible sin la vida propia." Grifos nossos.

${ }^{6}$ Fuentes apresenta uma sistematização metodológica do pensar sobre si. Ele separa os gêneros de expressão em quatro: Atos de conhecimento (examinar-se a si próprio); ideia de movimento (conversão do olhar voltando-se para si); vocabulário médico, jurídico, religioso (cuidar-se, sarar-se, reivindicarse); relação de controle (dar prazer a si mesmo). Estes gêneros de expressão possuem perspectiva de primeira pessoa, pois de fato, como seria possível olhar o mundo com o olhar do outro? A de conhecerse a si, para poder ampliar a lente da consciência, de modo que o olhar se alargue, amplie-se, tendo em vista as experiências conscientes, construindo espaços conceituais que somam as múltiplas perspectivas subejtivadas, servindo de base para que se tenha condições cada vez mais amplas de ler o entorno, o próprio mundo e em como se apresenta em suas configurações.
} 


\section{SEMINÁRIO DE PESQUISA EM CIÊNCIAS HUMANAS - SEPECH \\ Humanidades, Estado e desafios didático-científicos \\ Londrina, 27 a 29 de julho de 2016}

que transportam ação. Neste sentido, as palavras teriam certa natureza ontológica, assim como a matéria e a energia. Algumas teorias contemporâneas, que nasceram em ambientes inter, trans e multidisciplinares, defendem a tese de que a informação é de natureza ontológica ${ }^{7}$, ou seja, não é meio, é fim. De qualquer modo, para nos expressarmos e nos fazermos entender, sempre há a presença fenomênica de um discurso, seja ele de natureza ontológica ou revelado através de meio codificado é sempre entendido por palavras, estendendo o conceito metaforicamente para as relações de codificação e decodificação.

Ao encontrar caminhos possíveis de leitura de realidade, por meio de perspectiva plural, se pode lançar na busca de fontes inspiradoras, de temas mitológicos e históricos, concernentes a novas concepções técnicas e mapeamentos conceituais. Estas narrativas eram fontes da construção de zona fronteiriça entre a logicidade e o plano do fantástico. Quanto a esta zona fronteiriça, Foucault lançou um olhar arguto, sobre a própria concepção da realidade do sujeito.

Eu penso que o homem, se não é um sonho mau ou um pesadelo, pelo menos é uma figura bem particular, bem determinada historicamente situada no interior de nossa cultura. Antes do século XIX podemos dizer que o homem não existia. $\mathrm{O}$ que existia era um certo número de problemas, de formas, de saber e de reflexões; ou era questão de natureza ou da verdade, ou do movimento ou da ordem, ou da imaginação ou de apresentações etc.. Mas nunca, para dizer a verdade, era questão do homem. (FOUCAULT, 1966) ${ }^{8}$

Dobranszky ${ }^{9} \cdot$, ratificando a percepção foucaultiana, com pretensão de manterse no contexto da arte (com serventia a nosso propósito), argumenta sobre a razão engenhosa lida com a categoria prolífica da imaginação, ativada na percepção do detalhe (discernimento), que se identifica com a constituição da imagem (diagrama), em que há coerência na percepção das formas captadas da realidade sensível; em um sentido que não se dissocia da razão, mas faz parte dela. Ou seja, a imaginação em sua constituição do engenho é produtora de imagens associadas ao real e não à fantasia. Mediadora da relação entre o geral e o particular, a imaginação entendida como engenho, transita entre o caráter de necessidade presente nas leis naturais e o de probabilidade constituinte do aparato de racionalidade da natureza contingencial do humano. Excluir este fragmento do que poderíamos chamar de razoabilidade constitutiva é reduzir o próprio conceito de racionalidade, que deve ser revisado em suas raízes tradicionalmente aceitas, em outro dizer, um deslocamento de ponto de partida, anterior ao que adotamos como processo racionalmente formal.

\footnotetext{
${ }^{7}$ Recomendo a leitura do artigo: HASELAGER, W.F.G. \& GONZALEZ, M.E.Q.. A identidade pessoal e a teoria da cognição situada e incorporada. (Personal identity and the theory of embodied embedded cognition). In M.C. Broens, C.B. Milidoni, (Eds.). Sujeito e identidade pessoal: Estudos de filosofia da mente (pp. 95-111). São Paulo: Cultura Acadêmica, 2003.
}

${ }^{8}$ FOUCAULT, À propôs du livre 'Les mots et les choes'. (14 de junho de 1966). Disponível em: https://www.youtube.com/watch?v=XC7Ksv5tQso

Consultado em: 15 de maio de 2016. Tradução livre.

${ }^{9} 1992$, p. 48 


\title{
XI SEMINÁRIO DE PESQUISA EM CIÊNCIAS HUMANAS - SEPECH \\ Humanidades, Estado e desafios didático-científicos \\ Londrina, 27 a 29 de julho de 2016
}

O engenho é um dispositivo que, de certo modo, não se conforma com o estático, busca ideias que sejam as mais adequadas para responder a questões com maior especificidade, assim como com amplitude, e em suas normas são formuladas novas prerrogativas estritamente subjetivas e advindas dos sentimentos e instintos. Enfatizamos novamente, que o intuito não é de pender a balança para puros processos de subjetivação, mas, agregá-los ao todo do conhecimento e o reconhecermos como constituinte dos modelos de representação de realidade. Logo, a atividade do espírito deixa de ser negligenciada por uma natureza secretamente compartilhada, exposta em analogia, em oposições dialéticas. A tese de Cirne-Lima corrobora para a compreensão de como se desenvolve este processo de esclarecimento, a saber:

\begin{abstract}
A Quantidade é aqui um Quantum e possui um Limite, ou seja, ela é delimitada tanto em sua continuidade como em sua descontinuidade. Esse Limite, entretanto, não está num lugar determinado, mas onde ele estiver, ele estará delimitando a Quantidade e constituindo o Um; nesse sentido, ele é o princípio da continuidade. Esse Um é, pois, em primeiro lugar, a continuidade da Quantidade, que é em si e de si uma. Esse Um é, em segundo lugar, o princípio da descontinuidade, pois dele emerge a multiplicidade dos muitos Um, cada um diverso do outro. Esse Um é, em terceiro lugar, a unidade da continuidade e da descontinuidade, pois (a) ele refere-se a si mesmo em sua unidade, (b) ele deixa sair de si a multiplicidade dos muitos Um, cada um diverso dos outros, (c) e unifica em si tanto a continuidade quanto a descontinuidade. (CIRNE-LIMA, 2006, p. 51)
\end{abstract}

Cirne-Lima apresenta argumentos retirados da ciência da lógica de Hegel, que possui em seu bojo a descrição do desenvolvimento da consciente, do espírito, que, em seu primeiro passo, busca distinguir o si mesmo do outro, como uma atividade intrínseca ao próprio sujeito, não somente do pesquisador, como comumente se faz separar, como se o que se ocupa da pesquisa fosse de outra natureza que não a do humano. Há estruturas que são subjacentes a quaisquer de mesma espécie, e esta seria uma delas a atividade do distinguir o limite do Um e do Múltiplo, que em si possui ontologia, porém, contextualizando-o aos nossos propósitos para o momento, o limitamos modestamente à atividade do espírito dos sujeitos, com fim a apresentar subsídios conceituais que tragam estofo para nossa argumentação, a saber, que sujeito e objeto no âmbito da pesquisa estão intima e indissociavelmente relacionados, e que ao se discutir sujeito na pesquisa o que se faz é um trabalho relevante, pois o pesquisador é sujeito, que enquanto sabe de si, tanto mais sabe discernir o eu de um outro, o Um do múltiplo, e em quem há a consciência de que não existe neutralidade em nenhuma de suas escolhas, debruçando-se assim para um acuro maior para que sejam assertivas, por saber quais sejam suas responsabilidades inclusive éticas, que envolvem o ethos social, a coletividade de sujeitos. Saindo da condição alienante entendida como processo de objetivação, a pesquisa, toma outro rumo, concatenada ao corpo social em sua voz expressiva de quais os rumos que devemos tomar ao elegermos nossos critérios de relevância sobre como seria o melhor viver coletivo.

É sabido que Foucault não pretendeu escrever uma história do homem ou das ciências humanas e de seus desdobramentos. No entanto, o que traz à tona ao tecer a malha de sua arqueologia é questionar os fundamentos da lógica e da realidade, 


\title{
XI SEMINÁRIO DE PESQUISA EM CIÊNCIAS HUMANAS - SEPECH \\ Humanidades, Estado e desafios didático-científicos \\ Londrina, 27 a 29 de julho de 2016
}

desembocando na perspectiva de como se dimensiona uma imagem para o mundo esquematizado e vestido de racionalidade universal. $O$ que ele chamou de 'arqueologia' foi o escavar um conhecimento habitado em um lugar profundo, que ao estabelecer relações com a narrativa da historicidade revela que há uma inconsciência da ciência e do saber, porém deslocado instrumentalmente para o domínio da verdade.

Segundo Foucault, o homem é uma invenção cuja recente data apontada pela arqueologia mostra claramente; seguindo a narrativa de que o humanismo é uma espécie de cristalização que o anti-humanismo crítico poderia contestar, onde não se procura mais fronteiras comuns, sem a pretensão de salvar a ideia do homem iluminado, esclarecido, 'desalienado'. Considerar o homem prévio, configurado em sua objetividade, é o mesmo que encerrá-lo em um enunciado que não parece descrevê-lo, mas o torna uma fantasia, um delírio. O sujeito, sua singularidade, não cabe em um esquema, como não se pode substituir o sujeito pela ideia de humanidade.

Acrescentamos esta reflexão de Foucault:

\begin{abstract}
Não há semelhança sem assinalação. O mundo do similar só pode ser um mundo marcado. "Não é vontade de Deus", diz Paracelso, "que o que ele cria para o benefício do homem e o que lhe deu permaneça escondido... E ainda que ele tenha escondido certas coisas, nada deixou sem sinais exteriores e visíveis com marcas especiais - assim como um homem que enterrou um tesouro marca a sua localização a fim de que possa reencontrá-lo. (FOUCAULT, 1999, p. 35)
\end{abstract}

Para concluir, as conexões entre subjetividade, racionalidade e ciência são muitas e diversificadas, pois tanto o que sabemos a respeito do que seja a subjetividade, como o que seja a racionalidade e a ciência não é suficiente para delineá-las; estamos sempre a encontrar um passo a mais nos marcos antigos.

\section{REFERÊNCIAS}

CIRNE-LIMA, C. Depois de Hegel: Uma reconstrução crítica do sistema neoplatônico. Caxias do Sul - RS: Educs, 2006.

DESCARTES, R. Discurso do Método. In: Coleção Os Pensadores. São Paulo: Ed. Nova Cultural, 2004.

DESCARTES, R. Meditações. In: Discurso do Método. Meditações. Objeções e respostas. As Paixões da Alma. Cartas. Trad. B. Prado Júnior e J. Guinsburg. Notas G. Lebrun. 3 ed. São Paulo: Abril Cultural, 1983 (Coleção Os Pensadores).

DOBRANSZKY, E. A. No tear de Palas. Imaginação e gênio no século XVII: uma introdução. Campinas: Papirus, 1992.

DOMINGUES, D. (org.) Arte e vida no século XXI: tecnologia, ciência e criatividade. São Paulo: Ed. UNESP, 2003. 


\section{SEMINÁRIO DE PESQUISA EM CIÊNCIAS HUMANAS - SEPECH \\ Humanidades, Estado e desafios didático-científicos \\ Londrina, 27 a 29 de julho de 2016}

FOUCAULT, MICHEL. La hermenéutica del sujeto. Curso del College de France 1982. Ed. Akal, 2005.

O Nascimento da Clínica. Trad. De Roberto Machado. Rio de Janeiro: Forense-universitária, 1977.

As palavras e as coisas: uma arqueologia das ciências humanas. Trad. Salma T. Muchail. $8^{a}$ ed.. São Paulo: Martins Fontes, 1999.

À propôs du livre 'Les mots et les choes'. (14 de junho de 1966). Disponível em: https://www.youtube.com/watch?v=XC7Ksv5tQso Consultado em: 15 de maio de 2016.

FUENTES, Jesús C.. El valor en psicoterapia del término grecolatino "epimeleia heautou". Docta Ignorancia Digital, 2011; ISSN 1989 - 9416. Año II, núm. 2 Psicoterapia-Psicoanálisis, p. 55- 64. 